\title{
FERRAMENTAS DA ETNOFARMACOLOGIA NO AMBIENTE ESCOLAR: POTENCIAL PARA A EDUCAÇÃO AMBIENTAL?
}

\author{
Bruno Esteves Conde ${ }^{1}$ \\ Andréa Esteves Martins ${ }^{2}$ \\ Amanda Surerus Fonseca ${ }^{3}$
}

\begin{abstract}
Resumo: Dentre as ciências que podem interagir com a Educação Ambiental, têm se a Etnofarmacologia, que pode apresentar uma nova dimensão ao processo educacional. Sendo assim a presente pesquisa teve como objetivo a implantação de estratégias metodológicas no segmento da Etnofarmacologia na Escola Estadual Mercedes Nery Machado, como uma ferramenta alternativa para a Educação Ambiental, com desdobramentos para o ensino de Ciências, para proporcionar segurança no uso de plantas medicinais e incentivar a perpetuação dos conhecimentos culturais. Para o desenvolvimento metodológico, utilizou-se das seguintes técnicas: 1) Coleta de dados iniciais; 2) Coleta botânica com posterior identificação botânica; 3) Confirmação do uso seguro de plantas medicinais a partir de comparação com Anvisa - RDC n¹0; 4) Construção de horto medicinal escolar; 5) Inserção de ferramentas metodológicas do segmento da Etnofarmacologia na disciplina de Ciências, como recurso didático; 6) Promoção de evento de Fitoterapia na escola. Os resultados demonstraram que em relação às plantas medicinais, foi significativo, o aumento do conhecimento, da confiança, do interesse e da utilização entre os envolvidos na pesquisa. Notou-se também o aumento do interesse dos alunos pelos conteúdos de ciências, e a viabilidade da interdisciplinaridade na disseminação da educação ambiental. Sendo assim, tal ferramenta se mostra válida para a busca da conservação da biodiversidade, da perpetuação dos saberes culturais e também como alternativa para as aulas de Ciências, podendo assim ser seguida como modelo para outros trabalhos que venham a ocorrer no âmbito escolar.
\end{abstract}

Palavras-chave: Conservação da Biodiversidade; Ensino de Ciências; Perpetuação do Conhecimento Cultural; Plantas Medicinais. 


\section{Introdução}

Não é mais possível ignorar as repercussões das ações humanas no planeta (JACOBI, 2003). Neste sentido a relação entre o meio ambiente e a educação para a cidadania passa a assumir um papel cada vez mais relevante e desafiador, visto que os processos sociais vêm se complexificando, e os riscos ambientais se intensificando. Na tentativa de solucionar essa situação, têm-se a Educação Ambiental que quando implementada de forma adequada, pode proporcionar mudanças de valores (REIGOTA, 1998), para estimular maior integração e harmonia dos indivíduos com o meio ambiente.

A Educação Ambiental tem como objetivo a disseminação do conhecimento sobre o ambiente com propósitos de utilização segura e sustentável dos recursos naturais e conseguinte preservação da biodiversidade (SANTOS et al., 2011). Além disso, pode assumir a função de conscientização com relação ao consumismo cada vez mais aflorado no cenário atual, podendo servir como estimulador para mudança de valores individuais e coletivos (JACOBI, 2003).

Neste sentido, a escola torna-se um espaço privilegiado para a implementação efetiva da Educação Ambiental, podendo estabelecer conexões e informações para criação de condições e alternativas que estimulem os cidadãos a terem concepções e posturas ambientalmente corretas (LIMA, 1999).

Dentre as ciências que podem interagir com a Educação Ambiental concedendo ferramentas e possibilidades, têm se a Etnofarmacologia, que pode ser entendida como o estudo dos preparados tradicionais para fins medicinais, onde estão inseridas as plantas medicinais (ALBUQUERQUE; HANAZAKI, 2006). De acordo com Fernandes (2005), a Etnofarmacologia quando aliada a Educação Ambiental, pode apresentar uma nova dimensão ao processo educacional, valorizando informações que são veiculadas na informalidade das ações cotidianas e trazendo toda uma discussão sobre as questões ambientais, e as consequentes transformações de conhecimentos culturais.

As plantas são a identidade de um conjunto de pessoas, refletindo o que são o que pensam e suas relações com a natureza (MEDEIROS, 2004). O conhecimento cultural e prático das pessoas sobre as plantas medicinais encontra-se como um dos alvos dessas questões. Assim a Etnofarmacologia destaca-se, pois, através de suas ferramentas metodológicas, pode haver 0 desenvolvimento de atividades de Educação Ambiental (QUINTEIRO et al., 2013), que quando inserida no ambiente escolar servirá como meio disseminador das propostas de conservação e de sustentabilidade, levando em conta a diversidade cultural e biológica local (FERNANDES, 2005).

Com base no conceito de integração entre grupos de indivíduos, a Organização Mundial da Saúde (OMS) (1997), define que uma das melhores formas de se promover a saúde é através da escola. Isso porque, a escola é um espaço social, onde muitas pessoas convivem, aprendem e trabalham.

revista brasileira educação ambiental 
Também é o lugar onde os estudantes e os professores passam a maior parte de seus tempos, sendo propício também para práticas de disseminação da saúde. Além de ser um espaço que favorece a discussão e a repercussão, também pode beneficiar não só a comunidade escolar, mas também a sociedade em geral. Nesse sentido, os professores e todos os demais profissionais tornam-se exemplos positivos para os alunos, suas famílias e para a comunidade na qual estão inseridos (IRALA; FERNANDEZ, 2001).

O objetivo da presente contribuição foi promover na escola, a inserção da Etnofarmacologia, como ferramenta pedagógica através da implantação de estratégias metodológicas pela Educação Ambiental escolar, visando incentivar a conservação da biodiversidade, tendo em vista a busca pela sustentabilidade, e avaliar a presente ferramenta, como potencial recurso metodológico e alternativo para o ensino de ciências.

\section{Metodologia}

\section{Área de trabalho}

O trabalho foi realizado na Escola Estadual Mercedes Nery Machado, na cidade de Juiz de Fora, Minas Gerais (Figura 1), entre os meses de fevereiro a dezembro de 2010.

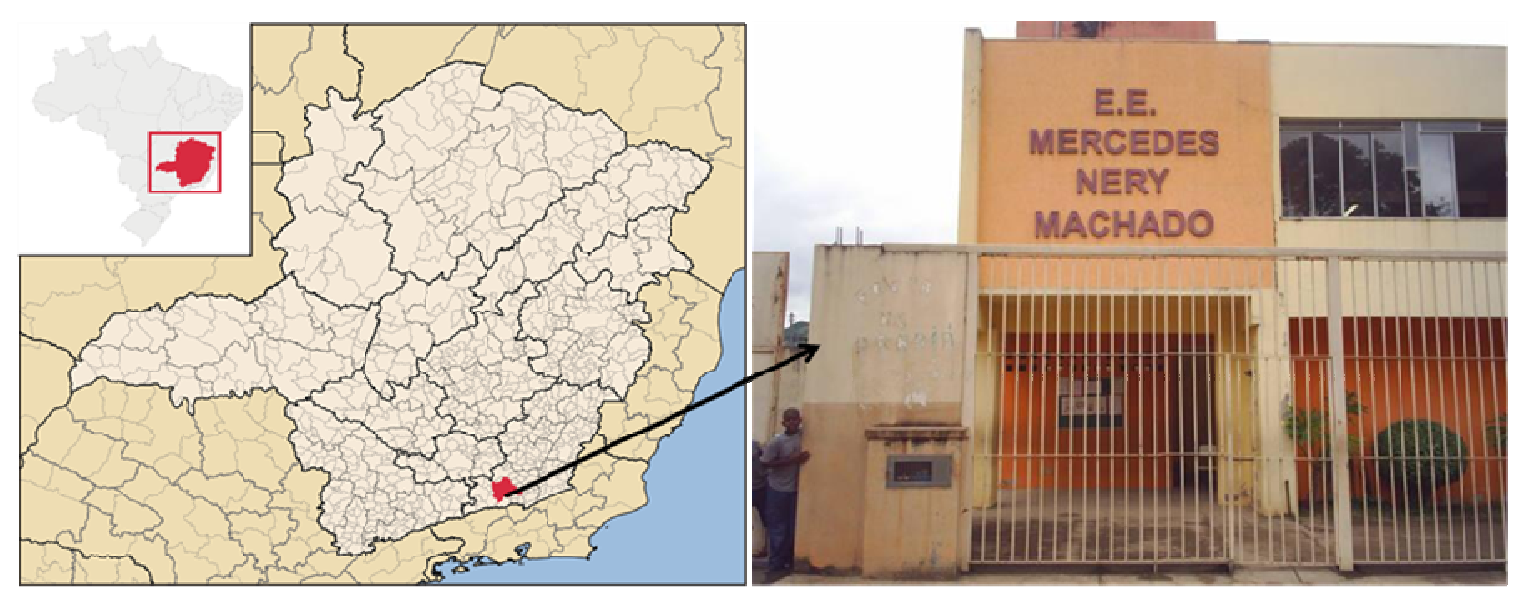

Figura 1: Localização geográfica, com destaque em vermelho para a cidade de Juiz de Fora e fachada da escola estadual Mercedes Nery Machado.

\section{Elementos / amostragem da pesquisa}

Foram envolvidos na referida pesquisa, alunos de $5^{\circ}$ ao $9^{\circ}$ anos da Escola Estadual Mercedes Nery Machado. Durante a realização da pesquisa havia um total de 354 alunos, com faixas etárias que variaram entre 8 a 16 anos. Também participaram 420 pais (ou responsáveis pelos alunos), 34 professores e demais funcionários, totalizando 808 participantes diretos e indiretos. 


\section{Apresentação e concordância da pesquisa}

Para que a pesquisa fosse desenvolvida, foram realizados dois encontros em fevereiro de 2010, entre pesquisadores, professores, coordenadores, alunos e pais ou demais responsáveis. Nestes encontros foram expostos os objetivos e desdobramentos da pesquisa. Ao término do encontro houve aprovação geral de todos os envolvidos.

\section{Técnicas}

\section{1) Coleta de dados iniciais}

Para a coleta de dados sociais e cadastrais dos alunos, foram utilizadas fichas de matrículas junto à secretaria da escola.

Para a coleta de dados etnofarmacológicos sobre plantas medicinais, foram preparados dois tipos de formulários semiestruturados específicos (ALEXIADES, 1996). O primeiro foi destinado aos alunos, e o segundo foi voltado para a aplicação junto aos pais e demais responsáveis.

As entrevistas realizadas com os alunos tiveram como perguntas: 1) Se conhecem alguma planta medicinal; 2) Caso conheça, quais são elas e para qual finalidade terapêutica as utilizam; 3) Com quem aprenderam; 4) Se confiam no poder das plantas medicinais: 4) Qual a nota de 0 a 10 atribuem ao seu interesse pelos conteúdos que sejam relacionados às plantas medicinais; 5) Qual a nota de 0 a 10 atribuem ao interesse nas aulas de ciências.

\section{2) Coleta de dados junto aos pais ou outros responsáveis}

Posteriormente, foi solicitado aos alunos que os mesmos realizassem entrevistas similares, com os formulários que haviam sido preparados para seus responsáveis. Nestes formulários haviam as seguintes perguntas: 1) Conhecimento sobre plantas medicinais 2) Se utilizam plantas medicinais 3) Qual a nota de 0 a 10, atribuem em relação a eficácia e a segurança sobre plantas medicinais.

Para a comparação dos dados, estes mesmos formulários foram reaplicados ao término do trabalho, de forma que para os alunos, a pergunta 3) de seus formulários fora transformada em, você aprendeu mais sobre plantas medicinais a partir do trabalho?

\section{2) Coleta Botânica e Identificação}

Ao realizarem as entrevistas com os familiares, os alunos tiveram como atividade complementar, a coleta das plantas medicinais, que haviam sido relatadas nos formulários aplicados pelos mesmos. Foi Solicitado aos alunos, a coleta das espécies floridas, que foram levadas então para a escola e secas em estufa (CONDE et al., 2014), fotografadas e posteriormente identificadas no 
Departamento de Botânica da Universidade Federal de Juiz de Fora por especialistas.

\section{3) Confirmação do uso seguro de plantas medicinais}

A partir dos dados coletados através das entrevistas e das posteriores identificações botânicas, comparou-se o uso terapêutico popular principal com as recomendação da Anvisa - RDC $n^{\circ} 10$. Com o intuito de que a intervenção pudesse contribuir também na qualidade de vida dos envolvidos. Sendo assim, buscou-se incentivar o uso daquelas que haviam tido seus principais usos respaldados pelo Ministério da Saúde através da Anvisa - RDC $n^{\circ} 10$, priorizando a segurança no uso de plantas medicinais.

\section{4) Construção de horto medicinal na escola}

Em um espaço verde da escola, com aproximadamente $25 \mathrm{~m}^{2}$, foram construídos quatro canteiros para plantio de mudas (Figura 2), utilizando-se de: garrafas pet, tambores plásticos, substratos com mistura de terra orgânica, húmus de minhoca e adubo (FETTER; MULLER, 2007), produzidos pela composteira e pelo minhocário, construídos em outra iniciativa desenvolvida anteriormente na escola. A escolha das mudas deu-se pela preferência (maior porcentagem de citação geral), e também pela segurança do uso, com base no RDC n॰10 da Anvisa.
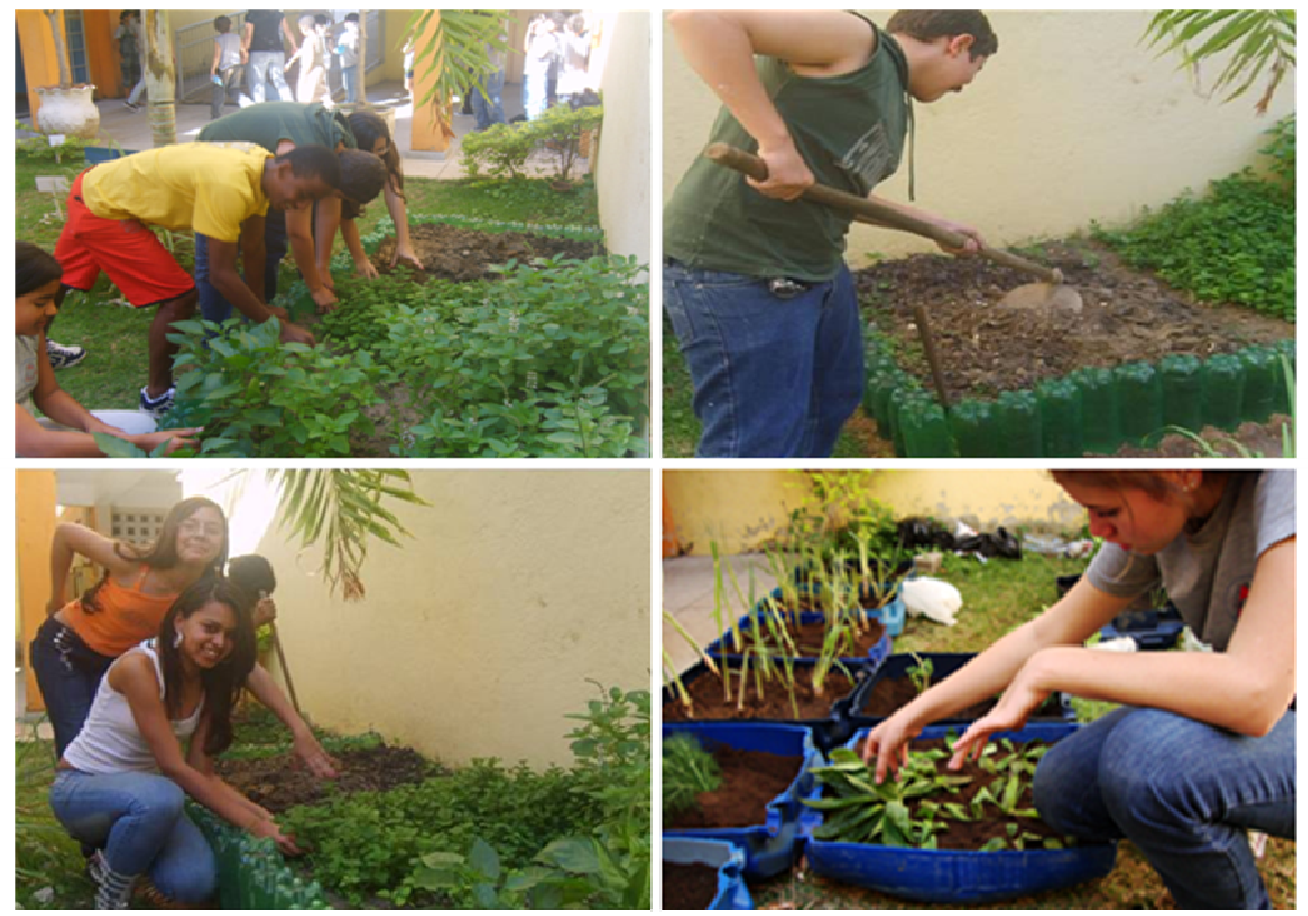

Figura 2: Processo de construção e implantação do horto medicinal escolar. 
5) Inserção de ferramentas metodológicas do segmento da Etnofarmacologia na disciplina de Ciências, como recurso didático

$\mathrm{Na}$ tentativa de avaliar o potencial das ferramentas metodológicas da Etnofarmacologia como recurso de incentivo e interesse ao conteúdo disciplinar das aulas de Ciências, foi solicitado que todos os professores desta disciplina, reservassem os 10 minutos finais de suas aulas para a explanação de temas relacionados às plantas medicinais no contexto da Educação Ambiental. Reforçando os benefícios relacionados ao uso dos recursos naturais para finalidades terapêuticas, tais como: minimizar gastos com medicamentos, aumentar áreas verdes, diminuir a poluição visual e contribuir para a conservação de espécies botânicas, promovendo a manutenção dos conhecimentos culturais com saúde e qualidade de vida. Também foi solicitado que pelo menos uma, a cada 10 aulas, acontecesse na horta medicinal escolar, e que a mesma fosse utilizada como laboratório ao ar livre com contextualização prática dos conteúdos explanados em sala de aula.

Para que houvesse meios de avaliar a presente etapa, foi realizada nova coleta de dados que ocorreu a partir da aplicação de entrevistas informais (BERNARD, 2006) com registro em diários de campo (SILVA, 2000), com os professores de Ciências da escola, onde foram abordados temas com relação à mudança de interesse dos alunos pela disciplina e a opinião quanto ao novo recurso pedagógico.

\section{6) Promoção de evento "Fitoterapia na Escola"}

Foi realizado um evento intitulado "Fitoterapia na Escola", no qual foram convidados pais, responsáveis, além dos alunos. Para a realização deste evento os alunos de cada uma das turmas envolvidas, foram divididos em grupos, sendo cada grupo responsável por elaborar e apresentar algumas espécies de plantas medicinais levantadas através do trabalho, abordando 0 método de preparo e a finalidade terapêutica, seguindo recomendações da Anvisa - RDC n० 10. Cada apresentação contou ainda com o oferecimento de um chá das referidas plantas para os convidados.

Ao término do evento, os participantes foram solicitados a responderem questionários estruturados (ALBUQUERQUE; LUCENA, 2004), distribuídos pelos pesquisadores e que contavam com as seguintes perguntas: 1) Se já acreditavam no poder terapêutico das plantas medicinais; e 2) Para os que desacreditavam, se houve alguma mudança de opinião após o evento. 


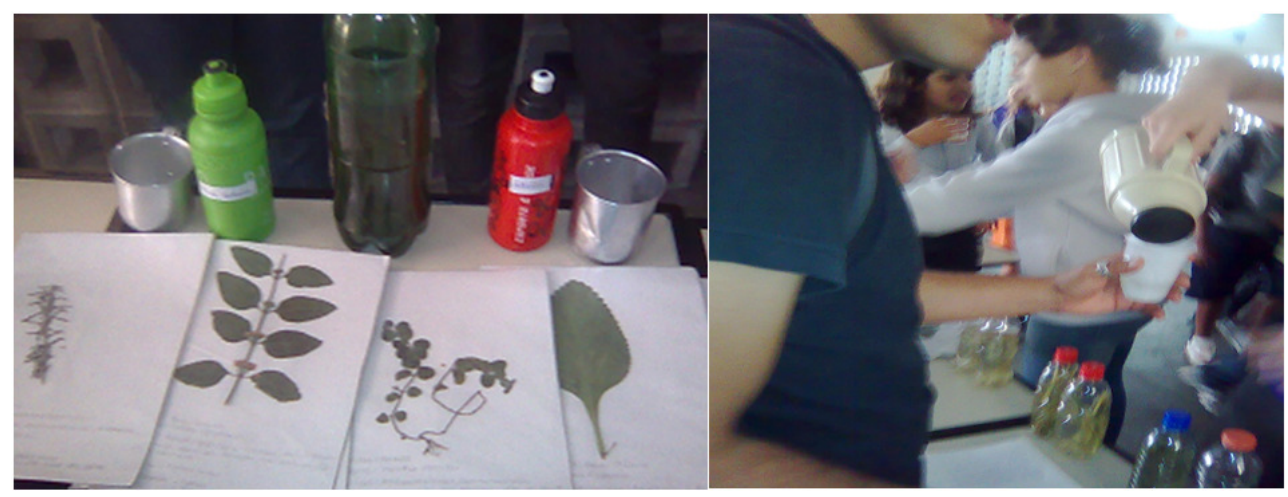

Figura 3: Encontro "Fitoterapia na Escola" com a participação de pais ou demais responsáveis e alunos.

\section{Resultados e discussões}

\section{Quanto à utilização das técnicas:}

1.1) Coleta de dados com relação aos alunos

Para o primeiro momento da coleta de dados, foram obtidos os seguintes resultados: 216 alunos (61\%) disseram ter algum conhecimento sobre plantas medicinais, sendo relatado por eles um acervo de 129 termos botânicos vernaculares, com 345 utilizações terapêuticas para os mesmos. Dos 216 que conheciam $199(92,1 \%)$ relataram ter aprendido com pais ou demais familiares, o que é confirmado por Amorozo (1996), que afirma que este tipo de conhecimento é transgeracional e perpetuado de forma oral pelo contato entre gerações, principalmente entre grupos domésticos e de parentescos.

Com relação à confiança no poder das plantas medicinais, dos 354 alunos entrevistados, $240(67,8 \%)$ relataram confiar nelas, sendo confirmado por 17 alunos que haviam passado a desacreditar nas plantas medicinais em função de um programa de televisão veiculado por uma grande emissora nacional que viera trazer inúmeros malefícios trazidos pelo uso das plantas medicinais. Esse evento pode ser confirmado por Tomazzoni et al., (2006) que citam eventos semelhantes que contribuem para a perda desse conhecimento, sendo a mídia a principal ferramenta para afastar as pessoas dos saberes empíricos.

Quanto ao interesse pelos conteúdos que tenham relacionado às plantas medicinais, a média foi de $5,27 \%$, o que pode confirmar a discussão anterior.

Para o segundo momento, e ao término da inserção de ferramentas metodológicas do segmento da Etnofarmacologia na disciplina de Ciências, como recurso didático, obteve-se os seguintes resultados: 330 alunos $(93,2 \%)$ passaram a ter algum conhecimento sobre plantas medicinais, 0 que demonstrou um aumento de 114 alunos (32,2\%) (Figura 4). Também foi possível constatar um aumento de 61 termos botânicos vernaculares e de mais 67 utilizações terapêuticas para estes, quando se comparado ao primeiro momento da coleta de dados. 


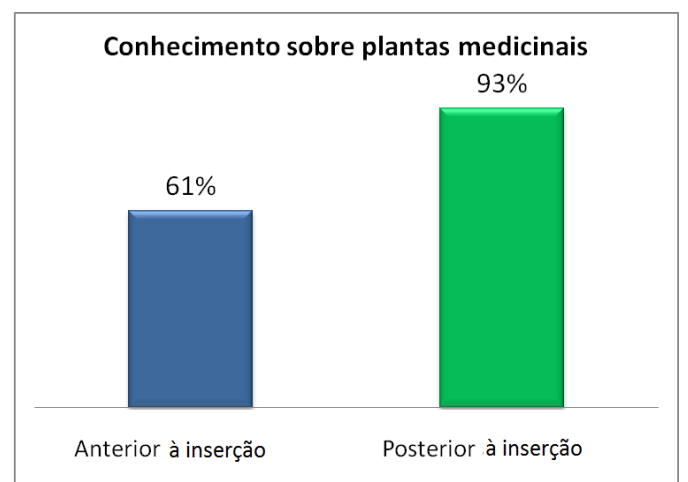

Figura 4: Comparação do conhecimento dos alunos sobre plantas medicinais em momento anterior e posterior da realização do trabalho.

Em relação à confiança no poder das plantas medicinais, $338(96 \%)$ dos alunos, passaram a relatar confiar nelas, o que demonstra um aumento de 98 pessoas (28,2 \%) (Figura 5).

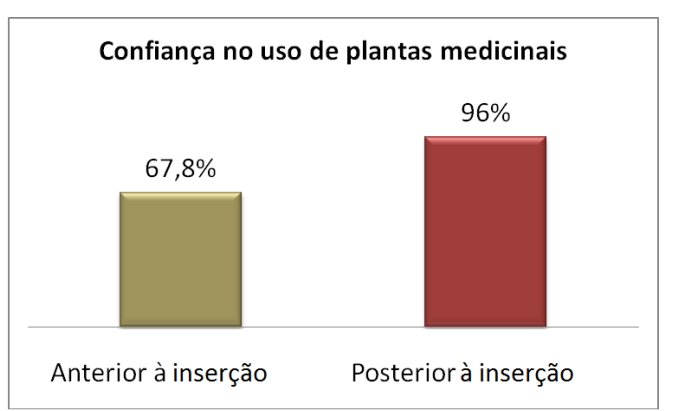

Figura 5: Confiança dos alunos no uso de plantas medicinais, em comparações quanto a momento anterior e posterior ao trabalho.

Quando foi perguntado se o conhecimento sobre as plantas medicinais havia aumentado a partir do trabalho, 351 alunos $(99,1 \%)$ responderam que passaram a conhecer sobre, ou complementaram seus conhecimentos préexistentes.

Quanto ao interesse pelos conteúdos que tenham relacionado às plantas medicinais, a média foi de 7, 77, aumentando em 2,5 (25\%) na média das notas quando em comparação com a etapa anterior (Figura 6). 


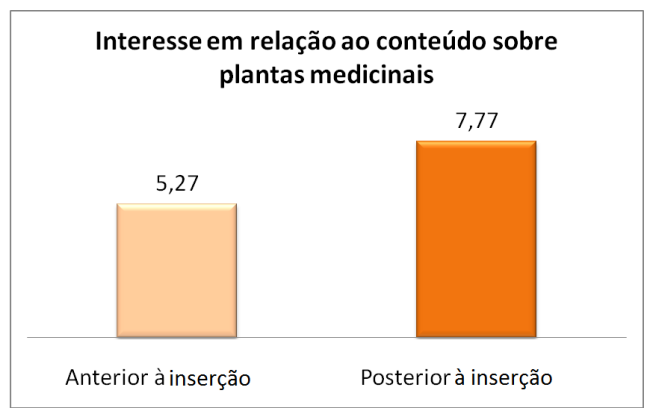

Figura 6: Interesse dos alunos em relação à conteúdos que abordam o estudo das plantas medicinais, em comparações quanto a momento anterior e posterior ao trabalho.

Estes resultados demonstram uma efetividade significativa quanto à inserção das ferramentas metodológicas do segmento da Etnofarmacologia na disciplina de Ciências, como recurso didático, para difusão de conhecimentos relacionados ao tema, plantas medicinais. Sendo assim, sugere-se que este modelo ou mesmo suas adaptações seja, seguidos de forma efetiva.

\section{2) Coleta de dados junto aos pais ou outros responsáveis}

Para o primeiro momento da coleta de dados, foram obtidos os seguintes resultados: 293 pessoas $(69,7 \%)$ relataram conhecer sobre plantas medicinais. Dentre as que relataram conhecer, $102(34,8 \%)$ relataram também fazer uso destas. A nota média atribuída em relação à informação, confiança quanto à segurança e eficácia do uso de plantas medicinais foi de 5,36.

Para o segundo momento da coleta de dados, ao término da inserção de ferramentas metodológicas do segmento da Etnofarmacologia na disciplina de Ciências, como recurso didático, foram obtidos os seguintes resultados: 408 $(97,1 \%)$ passaram a relatar ter algum conhecimento sobre plantas medicinais, aumentando em $115(27,4 \%)$, o número de usuários de plantas medicinais (Figura 7). Destes, 397 (97,3\%), passou a relatar fazer algum uso de plantas medicinais, o que representa um aumento de 295 pessoas $(69,9 \%)$ em relação à fase anterior (Figura 8).

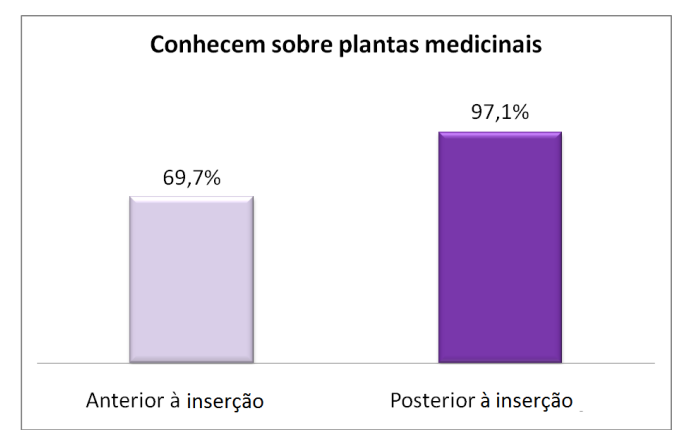

Figura 7: Conhecimento sobre plantas medicinais dos pais ou outros responsáveis pelos alunos, em comparações, de momento anterior e posterior ao trabalho.

Revbea, São Paulo, V. 9, N 1:116-131, 2014. 


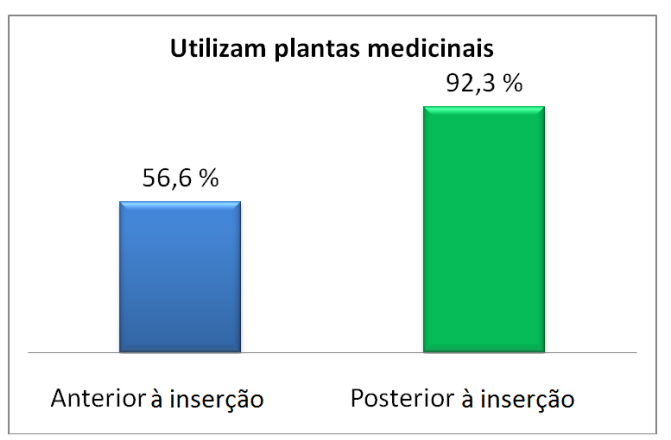

Figura 8: Utilização de plantas medicinais dos pais ou outros responsáveis pelos alunos, em comparações, de momento anterior e posterior ao trabalho.

A nota média para a informação, confiança quanto à segurança e eficácia do uso de plantas medicinais, foi de 8,0, significando um aumento 2,64 $(26,4 \%)$ em relação à média constatada anteriormente (Figura 9).

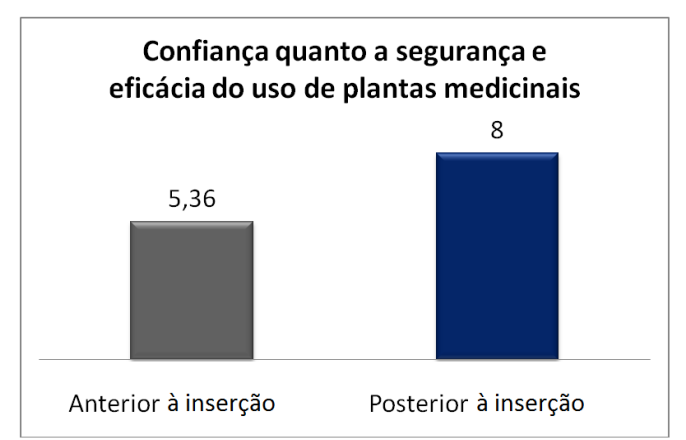

Figura 9: Confiança no uso de plantas medicinais dos pais ou outros responsáveis pelos alunos, em comparações, de momento anterior e posterior ao trabalho.

Tais resultados evidenciam o potencial da utilização das presentes ferramentas, como disseminadoras do conhecimento, não só entre alunos, mas também entre seus familiares, demonstrando efetividade e que segue as recomendações de Morin (2000), que afirma a necessidade de ações com tratamentos cada vez mais transversais, multidimensionais, globais e que venham buscar o tema "pensar global/agir local, pensar local/agir global".

\section{2) Coleta Botânica; e 3) Validação junto a Anvisa}

Através da coleta botânica, foi possível a identificação de 22 espécies de plantas medicinais, distribuídas em nove famílias botânicas com seus respectivos usos principais conforme as informações coletadas com os alunos e a comparação com a Anvisa RDC n¹0 (Tabela 1). 
Tabela1: Principais plantas medicinais do conhecimento dos alunos, com famílias botânicas, nomes científicos, nomes vernaculares e respectivas comparações com a Anvisa, para a validação do uso.

\begin{tabular}{|c|c|c|c|c|}
\hline $\begin{array}{l}\text { Família } \\
\text { Botânica }\end{array}$ & Nomenclatura científica/Origem & $\begin{array}{l}\text { Termo botânico } \\
\text { vernacular }\end{array}$ & Uso principal & Validado \\
\hline \multirow[t]{8}{*}{ Lamiaceae } & Mentha spicata $\mathrm{L}$. & Hortelã & Calmante & - \\
\hline & Mentha arvensis L. & Vique & Gripe & - \\
\hline & Plectranthus barbatus Andrews & Boldo & Indigestão & Sim \\
\hline & Ocimum gratissimum $\mathrm{L}$. & Alfavaca & Gripe & \\
\hline & Mentha pulegium $\mathrm{L}$. & Poejo & Gripe & \\
\hline & $\begin{array}{l}\text { Ocimum carnosum (Spreng.) Ligação } \\
\text { \& Otto ex Benth }\end{array}$ & Erva doce & Calmante & \\
\hline & Ocimum basilicum $\mathrm{L}$. & Manjericão & Indigestão & \\
\hline & Rosmarinus officinalis L. & Alecrim & Curar feridas & Sim \\
\hline \multirow[t]{6}{*}{ Asteraceae } & Ageratum conyzoides $(L.) \mathrm{L}$. & Erva São João & Colesterol alto & - \\
\hline & Mikania glomerata Spreng. & Guaco & Tosse & Sim \\
\hline & Baccharis trimera (Less) DC. & Carqueja & Emagrecer & - \\
\hline & Vernonanthura phosphorica (Vell.) & Assapeixe & Pneumonia e Gripe & Sim \\
\hline & $\begin{array}{l}\text { M.KOD. } \\
\text { Bidens pilosa } \mathrm{L} \text {. }\end{array}$ & Picão & Amarelão e Hepatite & Sim \\
\hline & Foeniculum vulgare Mill & Funcho & Calmante e gases & Sim \\
\hline Poaceae & Cymbopogon citratus (DC) Stapf. & Capim Limão & Calmante & Sim \\
\hline Rutaceae & Ruta graveolens $\mathrm{L}$. & Arruda & Conjuntivite & - \\
\hline \multirow[t]{2}{*}{ Crassulaceae } & Kalanchoe laciniata (L.) DC. & Saião & Dor de estômago & - \\
\hline & Aloe vera (L.) Burm. f. & Babosa & Problemas de pele & - \\
\hline Costaceae & Costus spicatus (Jacq.) Sw. & Cana de Macaco & Infecção urinária & - \\
\hline Plantaginaceae & Plantago major $\mathrm{L}$. & Transagem & Inflamação da garganta & Sim \\
\hline Phyllanthaceae & Phyllanthus tenellus Roxb. & Quebra Pedra & Pedra nos rins & \\
\hline Verbenaceae & $\begin{array}{l}\text { Lippia alba (Mill.) N.E.Br. ex Britton } \\
\& \text { P.Wilson }\end{array}$ & Erva cidreira & Calmante & Sim \\
\hline
\end{tabular}

Os resultados apontam para uma significativa coincidência entre as plantas do conhecimento cultural dos alunos, já que nove das 22 espécies identificadas, foram confirmadas diante as recomendações da Anvisa - RDC $n^{\circ} 10$.

\section{4) Implantação do horto medicinal escolar}

Para a implantação do horto medicinal escolar, utilizou-se de materiais reutilizáveis, tais como: garrafas PET e tambores plásticos. Neste sentido, os professores puderam mostrar como é possível construir espaços com materiais que virariam lixo, e que poderiam levar muitos anos até que a natureza conseguisse decompô-los. A partir da implantação do horto, os professores de outras disciplinas como Geografia e Artes, utilizaram o espaço, trabalhando diferentes conteúdos e colocando em prática a interdisciplinaridade com os seus alunos. As Ciências Naturais, juntamente com a Matemática, puderam se utilizar do horto, como recurso para: explicar diferentes formas de cultivo de alimentos, estudar o crescimento e desenvolvimento dos vegetais, enfatizar a importância da terra e de seus nutrientes, e buscar a relação matemática no estudo das fases dos ciclos de vida dos vegetais, bem como sua produtividade. Essas atividades também asseguram aos alunos e à escola o resgate da cultura local e, consequentemente, estilos de vida mais saudáveis (IRALA; FERNANDEZ, 2001). 
Após o encerramento do trabalho foi confirmado por $22(88 \%)$ dos professores da escola, que através de tal iniciativa, foi possível o contato direto com a natureza, e o que segundo eles possibilitou ao aluno reflexões sobre valores do meio natural, o que de acordo com Meyer (1991), pode ser tratado como aprendizado vivencial, e que pode favorecer a produção de diálogos sobre o meio ambiente com produção de um repensar coletivo entre os mesmos.

Através da construção do horto medicinal escolar pela Etnofarmacologia no segmento da Educação Ambiental, os alunos são levados a reconhecer valores e contextualiza-los com os locais onde vivem, já que, segundo Tabanez (1996), existe uma relação direta entre a conservação ambiental e o cotidiano escolar. Sendo assim, através do contato direto com a natureza, pode haver a estimulação da criatividade e o consequente interesse pelos conteúdos disciplinares, podendo facilitar o processo de ensino e aprendizagem, contribuindo assim com toda a educação escolar (MERGULHÃO; VASAKI, 1998; SANTOS, 2007).

Por terem sido implantadas apenas espécies confirmadas através comparação com a Anvisa - RDC $n^{\circ} 10$, o referido horto, seguiu o modelo "Farmácias Vivas" (MATOS, 1994), proporcionando segurança e eficácia do uso de plantas medicinais, com manutenção dos saberes culturais dos participantes.

\section{5) Promoção do evento "Fitoterapia na Escola"}

Com relação ao evento, estiveram presentes 240 pessoas, das quais 60 eram pais ou responsáveis dos alunos. Destes, $34(56,6 \%)$ relatou confiar no poder terapêutico das plantas medicinais, anteriormente a realização do evento. Entre os 26 que não confiavam 22 (92,3\%) (Figura 10) relataram passar a acreditar no poder terapêutico das plantas medicinais, após a realização do evento. Este resultado demonstrou o potencial desta iniciativa, como ferramenta complementar e potencializadora no âmbito na referida pesquisa.

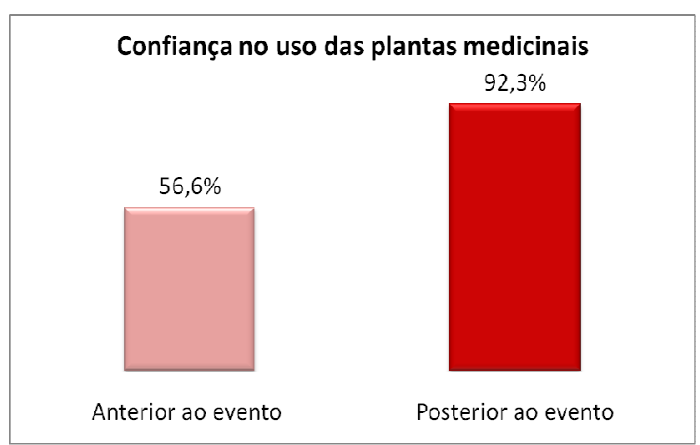

Figura 10: Confiança no poder terapêutico do uso de plantas medicinais, dos pais ou outros responsáveis dos alunos, em comparações com momento anterior e posterior ao evento" Fitoterapia na Escola"

Revbea, São Paulo, V. 9, Nº 1: 116-131, 2014.

revista brasileira educação ambiental 
Os resultados atendem às recomendações de Carvalho (2000), para a Educação Ambiental, que deve buscar aliar mudanças de sentimentos e conhecimentos, priorizando programas que coloquem os alunos em contato com a natureza.

Embora esta iniciativa metodológica possa demandar mais tempo e esforço, recomenda-se a utilização da mesma com base em Freire (1998), para proporcionar a mudança de valores e atitudes da sociedade.

6) A avaliação da inserção de ferramentas metodológicas do segmento da Etnofarmacologia como recurso didático para o ensino de Ciências

Contatou-se que cinco (100\%) dos professores de Ciências avaliaram positivamente, às ferramentas metodológicas da Etnofarmacologia como recurso de incentivo e interesse com relação ao conteúdo disciplinar das aulas de Ciências, além de servir como potencial para a disseminação da Educação Ambiental voltada para a conservação da biodiversidade.

Também se constatou que os mesmo cinco professores, passaram a se interessar, ou interessar mais pelo tema plantas medicinais. Três destes relataram não haver uma disciplina acadêmica com o respectivo tema para a formação de professores no ensino superior, o que pode sugerir um possível distanciamento do conhecimento empírico com relação ao acadêmico. Nesta perspectiva, tem-se a Etnofarmacologia, que de acordo com Waller (1993), tem como objetivo resgatar e avaliar a eficácia das técnicas "tradicionais" sobre a utilização de plantas para fins terapêuticos, o que pode relacionar o conhecimento empírico com o científico.

\section{Conclusão}

Ficou evidente a participação e o comprometimento dos alunos e dos respectivos familiares em todas as etapas do trabalho.

Foi possível concluir que as ferramentas da Etnofarmacologia foram potencialmente efetivas quando relacionadas à Educação Ambiental, servindo também como alternativa metodológica para o ensino de Ciências, contribuindo de forma eficaz para a difusão do uso sustentável dos recursos naturais entre os alunos da Escola Estadual Mercedes Nery Machado e de seus familiares, reforçando a ideia de conservação e respeito pelos recursos advindos da natureza.

Quanto à implantação do horto medicinal escolar, foi possível trabalhar os conteúdos disciplinares de maneira interdisciplinar, promovendo a manutenção dos conhecimentos Etnofamacológicos, com a aproximação do conhecimento cultural do científico, proporcionando a utilização segura das plantas medicinais.

O presente trabalho poderá servir como modelo para iniciativas futuras e similares no quesito conservação da biodiversidade pela Educação Ambiental. 
Reforçando também a importância de iniciativas, para a busca por mudanças de valores relacionados ao meio ambiente. Sendo assim, demonstra-se a importância de se produzir conhecimento que venha contemplar as interrelações entre o meio natural com o social, para a sustentabilidade socioambiental.

\section{Agradecimentos}

Aos alunos, pais, professores, funcionários da Escola Estadual Mercedes Nery Machado, em especial a diretora Ana Lúcia Ribeiro, a vicediretora Inêz de Oliveira e a Supervisora Eliane Lomeu.

\section{REFERÊNCIAS}

ALBUQUERQUE, U.P.; HANAZAKI, N. As pesquisas etnodirigidas na descoberta de novas drogas de interesse médico e farmacêutico: Fragilidade e perspectivas. Revista Brasileira de Farmacognosia. Curitiba, v. 16, p. 678689. 2006.

ALBUQUERQUE, U. P.; LUCENA, R. F. P.. Métodos e técnicas para a coleta de dados. In: ALBUQUERQUE, U.P.; LUCENA, R. F. P. (Ed.). Métodos e Técnicas na Pesquisa Etnobotânica. Recife: Livro Rápido/NUPEEA. pp. 39159. 2004.

ALEXÍADES, M. Selected guidelines for ethnobotanical research: a field manual. New York:The New York Botanical Garden. 1996.

AMOROZO, M.C.M. A abordagem etnobotânica na pesquisa de Plantas Medicinais. In: DI STATSI, L.C. (Org.). Plantas medicinais: Arte e Ciência, um guia de estudo interdisciplinar. São Paulo: EDUSP, 1996.

BERNARD, H.R. Research methods in cultural anthropology. 4ed. USA: SAGE Publication, 2006.

BRASIL. ANVISA. Resolução RDC nํ 10, de 09 de março de 2010. Brasília, DF: Diário Oficial da República Federativa do Brasil, 2010.

CARVALHO, L.M. Falta sistematizar melhor a Educação Ambiental. São Paulo: WWF Brasil, 2000.

CONDE, B.E; ROGÉRIO, I.T.S.; SIQUEIRA, A.M; FERREIRA, M.Q; CHEDIER, L.M; PIMENTA, D.S. Ethnopharmacology in the vicinity of the Botanical Garden of the Federal University of Juiz de Fora, Brazil. Ethnobotany Research and Applications. v. 12, p. 91-111. 2014.

FERNANDES, P.C. Etnofarmacologia como ferramenta para a educação ambiental. Dissertação de Mestrado. Universidade Estadual de Campinas. 2005. 
FETTER, S. I.; MÜLLER, J. Agroecologia, merenda escolar e ervas medicinais. Resgatando valores no ambiente escolar. Revista Brasileira de Agroecologia. Porto Alegre, v.2, n.1, p. 319-320. Fev/2007.

FREIRE, P. Pedagogia da Esperança: reencontro com a Pedagogia do Oprimido. 5a ed. São Paulo: Paz e Terra, 1998.

IRALA, C.H.; FERNANDEZ, P.M. A escola promovendo hábitos alimentares saudáveis. Brasília: Universidade de Brasília, 2001.

JACOBI, P.R. Educação Ambiental, Cidadania e sustentabilidade. Cadernos de Pesquisa. São Paulo, n.118, p. 89-205, mar/ 2003.

LIMA, G.C. Questão ambiental e educação: contribuições para o debate. Ambiente e Sociedade. São Paulo, ano. 2, n. 5, p. 135-153, dez/1999.

MATOS, F.J.A. Farmácias vivas. João Pessoa: UEFC. 1994.

MEDEIROS, M.F.T; FONSCECA, V.S.; ANDREATA, R.H.P, Plantas Medicinais e seus usos pelos sitiantes da Reserva das Pedras, Mangaratiba, RJ, Brasil. Acta Botânica Brasílica, Rio de Janeiro, v. 18, n.2, p. 391-399, 2004.

MERGULHÃO, M.C; VASAKI, B.N.G. Educando para Conservação da Natureza. São Paulo: EDUC, 1998.

MEYER, M.A.Z. Educação Ambiental: uma proposta pedagógica. Em Abertotema. Brasília: INEP, v. 49, p. 41-46, mar/1991.

MORIN, E.A. Os sete saberes necessários à educação no futuro. São Paulo: Cortez, 2000.

Organização Mundial da Saúde (OMS): Declaração de Jakarta. In: Promoção da Saúde e Saúde Pública. Rio de Janeiro: ENSP, 1997.

QUINTEIRO, M.M.C.; TAMASHIRO, A.M.G.; MORAES, M.G. Formas de retorno da pesquisa etnobotânica à comunidade no paradigma da complexidade ambiental e educação ambiental. Revista Brasileira de Educação Ambiental. Rio Grande, vol.8 n. 1, p. 91-99. Jan/2013.

REIGOTA, M. Desafios à educação ambiental escolar. In: JACOBI, P.R. et al. (orgs.). Educação, meio ambiente e cidadania: reflexões e experiências. São Paulo: SMA, 1998.

SANTOS, J.G.; NASCIMENTO, N.M.S.; SILVA, S.S.F.; RAMALHO, A.M.C.; Educação ambiental, cidadania e sustentabilidade: Um estudo com alunos do ensino fundamental. Revista Educação Ambiental em Ação. Florianópolis, $n^{\circ}$ 48. Dez/2011.

SANTOS, L.P.S. Contextualização no ensino de ciências por meio de temas CTS em uma perspectiva crítica. Ciência \& Ensino, Campinas, vol. 1, Nov/2007.

SILVA, V.G. O Antropólogo e sua Magia. São Paulo: Ed. EDUSP. 2000. 
TABANEZ, M.F. A eficácia de um curso de educação ambiental não formal para professores numa área natural. Estação Ecológica dos Catetos- SP. Revista do Instituto Florestal de São Paulo. São Paulo, v. 8, p. 71-88. Jun/1996.

TOMAZZONI, M.I.; NEGRELLE, R.R.B.; CENTA, M.L. Fitoterapia popular: a busca instrumental enquanto prática terapeuta:: Texto \& Contexto Enfermagem. Florianópolis, v.15, n. 1. 2006.

WALLER, D.P. Methods in ethnopharmacology. Journal of Ethnopharmacology. v. 38, p.189-195. Mar/1993. 